\title{
ELEMENTAL ANALYSIS OF AYURVEDIC DRUGS (BHASMAS) BY ATOMIC ABSORPTION SPECTROMETER
}

\author{
ASHWINI A ${ }^{1}$, KERUR BR ${ }^{2 *}$ \\ ${ }^{1,2}$ Department of Physics, Gulbarga University, Kalaburagi, Controller of Examination, Central University of Karnataka, Kadaganchi, Aland \\ road - 585367, Karnataka, India. Email: kerurbrk@gmail.com
}

Received: 28 December 2018, Revised and Accepted: 19 January 2019

\section{ABSTRACT}

Objective: Ayurvedic drugs/bhasmas are very potent and promising drugs for the treatment of various ailments. Bhasmas are the multielement samples, and the present work deals the analysis of the concentration of metallic elements in three ayurvedic bhasmas of four different brands, to compare and know the quality of commercial bhasma in market.

Methods: Commercially available abhraka bhasma (AB), mandoor bhasma (MB), and godanti bhasma (GB) in market from four different manufacturing companies were procured, and bhasma sample solution was prepared to analyze the elemental concentrations in bhasma; the solution is subjected to flame atomic absorption spectrometer (FAAS) technique and determined elemental concentration in bhasmas of four different commercial brands.

Results: FAAS analysis explores the presence of $\mathrm{Mg}, \mathrm{Al}, \mathrm{K}, \mathrm{Ca}, \mathrm{Cr}, \mathrm{Mn}, \mathrm{Fe}, \mathrm{Cu}, \mathrm{Zn}, \mathrm{Mo}$, and Cd elements concentration in three bhasmas/drugs by four manufacturers. $\mathrm{AB}$ is rich in $\mathrm{Al}$ and Fe following the other elements in low concentrations, $\mathrm{MB}$ is rich in $\mathrm{Fe}, \mathrm{Ca}, \mathrm{Mn}, \mathrm{Cu}, \mathrm{K}$, and $\mathrm{Al}$ and other elements are present in less quantity, and GB is rich in Ca and all other elements were very less in quantity.

Conclusion: FAAS analysis showed that there is a difference in quantity/concentration of elements present in bhasma, aluminum (Al) is found high in Patanjali brand bhasmas compared to other three brands, and the toxic metal cadmium (Cd) is found in Dhootapapeshwar mandoor bhasma (DMB) $(0.0458 \mathrm{mg} / \mathrm{l})$, except DMB, all bhasmas found free from toxic metals, which reveal that there is a variation in quality of bhasmas from different manufacturers, and the elements present in bhasmas are found to be in permissible range for human intakes. As the mineral elements are essential in human diet, if the amount of any elements becomes too high in body, then it can affect the functioning of other important minerals in body causing the severe health problems, so it is must, to balance all nutrients in human diet, either through food or medicines. Hence, the present analysis work focuses on the variation of concentrations of elements present in bhasma of different manufacturers, which will help in practitioners to compare and refer good quality bhasmas or drugs in terms of their ingredients/elements, which plays a major role in functioning of human body normally. Further work is necessary to carry out on bhasmas and ayurvedic formulations in order to get the good diet supplementations.

Keywords: Flame atomic absorption spectrometer, Abhraka bhasma, Mandoor bhasma, Godanti bhasma, Elemental analysis, WHO/Food and Agriculture Organization, Recommended daily intake.

(C) 2019 The Authors. Published by Innovare Academic Sciences Pvt Ltd. This is an open access article under the CC BY license (http://creativecommons. org/licenses/by/4. 0/) DOI: http://dx.doi.org/10.22159/ajpcr.2019.v12i3.31026

\section{INTRODUCTION}

Ayurveda is one of the world's oldest traditional medicinal systems and is experiencing revitalization among the consumers throughout the world. In Ayurveda, medicines are prepared by adding minerals of various metals, parts of plants, plant juices, alloys, etc., for the treatment of different illness. Bhasma, literally meaning ash, is unique ayurvedic herbomineral/metallic formulations of nanodimension [1]. The fine copper $(\mathrm{Cu})$ metal, tin $(\mathrm{Sn})$, zinc $(\mathrm{Zn})$, and iron (Fe) metals were used as primary elements in bhasma formation [2]. In ayurvedic system of medicine, the variation in collection process, timing and procedure adopted, may lead the same bhasma with different quality aspects. In many cases, wrong process of manufacturing and marketing of the same may lead to production of inferior-quality products, which reduces efficacy of products as well as safety parameters. Standardization of a bhasma is essential to minimize unevenness and to strengthen the quality of ayurvedic products [3]. Very fine bhasmas give very significant effect as compared to coarse one [4]. During preparation, there will be chances of contamination of various chemicals such as arsenic, lead, silica, and mercury, which cause toxic effect on body, so there is need to take proper precaution during preparation of bhasma.

In the literature, elemental analysis of bhasma has been reported by estimation of the amount of elemental calcium in herbomineral preparation and revealed that herbomineral drugs developed by wet granulation method are better formulation in case of calcium-deficiency ailments [5]. Analysis of copper element in tamra bhasma of different batches and different manufacturers was made [6]. X-ray diffraction (XRD) report is available on the raw swarna makshika, purified swarna makshika, and four types of swarna makshika bhasma prepared by different media and by modern Instrumentation techniques [7]. Quality of the prepared Pravala bhasma was checked [8]. Earlier, the quality of the ayurvedic preparations was not subjected to review, but with technological development, the patients or the physicians seek assurance for the quality, safety, and efficacy of any medicine [9]. Researchers have made attempt to compare the laboratory-formulated varatika bhasma and varatika bhasma available in market, by evaluating the physical properties and chemical characterization using atomic absorption spectroscopy (AAS), Scanning Electron Microscope (SEM), and X-ray Diffractometer (XRD) [10]. Different marketed products of mandur bhasma were analyzed by physicochemical evaluation and modern analytical technique [11] to evaluate the hepatotoxicity in rats. One of the authors had carried out biosynthesis approach to prepare $\mathrm{FeO}$ nanoparticles from the iron chloride solution using aqueous extract of desmodium gangeticum root [12]. Human body requires inorganic substances called minerals to function properly. Minerals required in large amount of body are considered as macrominerals, such as $\mathrm{Ca}, \mathrm{Mg}$, 
and $\mathrm{K}$, and minerals required in minute amount called trace elements / minerals, such as $\mathrm{Cu}, \mathrm{I}, \mathrm{Fe}, \mathrm{Mn}, \mathrm{Cr}$, and $\mathrm{Zn}$. There is a noticeable point that if any one of the trace elements becomes too high in body, it can affect the function of other important trace minerals in body. For example, absorption of zinc can become impaired if iron supplementation level approaches to $45 \mathrm{mg}$ /day. Similarly, high level of zinc supplementation can lead to low copper levels and altered iron functionality. Similarly, sodium and potassium are both major minerals that are essential for health in appropriate amounts. Eating lot of sodium can cause some people to lose calcium from the bones, which could increase the risk of bone loss and bone fractures. The copper deficiency could be due to impairment in its uptake and is caused by the presence of additional heavy metals in the diet that completely diminishes copper uptake in the lining of gastrointestinal tract. Molybdenum is the most common competitor of copper absorption [13].

In literature, there is less information found on marketed bhasmas which are, in general easily available to people, people use to take ayurvedic medicines without concerning to physician, so the safety and efficacy of ayurvedic medicines should be taken care by manufacture. The aim of this work is comparative analysis of commercially available three bhasmas of four different brands by determining the elemental content of each brand bhasma through flame atomic absorption spectrometric (FAAS) technique and to check quantitatively the presence of elements are well within the permissible range of intake.

\section{MATERIALS AND METHODS}

\section{Sample collection}

Abhraka bhasma (AB), mandoor bhasma (MB) and godanti bhasma (GB) of four manufacturers, namely Divya Patanjali, Shree Baidyanath, Shree Dhootapapeshwar, and Ayukalp company sample were purchased from the market in India, and the details of purchased bhasma were represented in Table 1; all other ingredients required in sample preparation such as concentrated hydrochloric (HCL) acid, doubledeionized water, Whatman filter paper, and acetone of analytical grade were purchased from Shree Venkatesh Chemical Lab, Kalaburagi, India.

\section{Sample preparation}

For the analysis of element constituent in the bhasma samples, the standard solution preparation of elements for the FAAS, bhasmas sample solutions are prepared, i.e., solution of $50 \mathrm{ml}$ is prepared in the proportion of 1:25:25 ratio, i.e., 1 gm of bhasma sample is digested in $25 \mathrm{ml}$ concentrated HCL plus $25 \mathrm{ml}$ of double-deionized water and kept the solution for digestion through a night and filtered the solution by Whatman filter paper, again this $50 \mathrm{ml}$ solution is diluted by adding $950 \mathrm{ml}$ of Double Deionized water finally, $1000 \mathrm{ml}$ bhasma solution was prepared which is used for the elemental analysis. Using the standards of individual elements, the calibration of instrument was checked and the lamps of different characteristic wavelengths were used for the different elemental analysis.

\section{Instrumentations}

Elemental analysis of bhasmas was carried out by FAAS which was supplied by Thermo Scientific, with iCE 3000 series. The instrumentation setting and operation conditions were done in accordance with manufacturer's specification.

\section{Data analysis}

An analytical technique, namely FAAS, measures the concentrations of elements in unit of mg/l. FAAS absorption is so sensitive that it can measure down to parts per million or billion of a gram in a sample. The technique uses the characteristic wavelengths of light which is specifically absorbed by a specific element. Element of different atoms absorbs the characteristic wavelengths of light. For example with mercury, a lamp containing mercury emits light from excited mercury atoms that produce the right mix of wavelengths to be absorbed by any mercury atom from the sample. In FAAS, the sample is atomized, i.e. converted into ground-state free atoms in the vapor state, and a beam of electromagnetic radiation emitted from excited mercury atoms is passed through the vaporized sample. Some of the radiation is absorbed by the mercury atoms in the sample. The more radiation is absorbed by the atoms if the number of atoms is more in the vapor. The amount of light absorbed is proportional to the number of mercury atoms. A calibration curve is constructed by running several samples of known element, namely copper, potassium, and calcium concentration under the same conditions as the unknown. The amount of standard absorbed is compared with the calibration curve, and this enables the calculation of the lead concentration in the unknown sample. Similar process follows in the case of all other elements in the sample solution under examination.

\section{RESULT AND DISCUSSION}

In the present analysis, eleven elements were determined in Abhraka, Mandoor, and Godanti Bhasma and are presented in Tables 2-4 respectively. In Tables $2-4$, the first column indicates the symbol of mineral element bar (/) the recommended daily intake (RDI) [14] of the respective elements. Moreover, columns 2, 3, 4, and 5 indicate that the determined concentration level of elements (mean \pm standard deviation) measured in mg/l belongs to Divya Patanjali, Shree Baidyanath, Shree Dhootapapeshwar, and Ayukalp brand, respectively. In all the three bhasma taken here, magnesium $(\mathrm{Mg})$, potassium $(\mathrm{K})$, calcium $(\mathrm{Ca})$, manganese $(\mathrm{Mn})$, and zinc $(\mathrm{Zn})$ are found to be present in below the RDI level [14].

\section{Abhraka bhasma}

It is produced by repeated incineration of mica with specific medicinal herbs, which is referred as nanomedicine and is often used in the treatment of a variety of ailments, particularly those arising due to oxidative stress. AB was used as a major component of rejuvenating or antiaging formulations. Table 2 represents the elemental concentrations of $\mathrm{AB}$ in $\mathrm{mg} / \mathrm{l}$ by $\mathrm{AAS}$

Table 1: Details of bhasmas

\begin{tabular}{|c|c|c|c|c|c|}
\hline Samples & Manufacturing license number & Batch number & Manufacture date & Method used in preparation & Price per gm \\
\hline PAB & Uttra/Ayu-67/2005 & ABB027 & November 2015 & AFI-I & $13 / 5$ \\
\hline $\mathrm{BAB}$ & $\mathrm{ND} / \mathrm{AYU} / 4$ & 150099 & June 2015 & RasRaj Sunder & $86 / 10$ \\
\hline DAB (Shataputi) & AYU-150 & P1610100364 & January 2016 & SDS Monograph no-020001 & $126 / 2$ \\
\hline $\mathrm{AAB}$ & GA/1701 & ВНВ028 & August 2014 & RTS Vol1 & $70 / 10$ \\
\hline PMB & UA-AYU-67/2005 & MDB025 & January 2015 & AFI-I & $15 / 5$ \\
\hline BMB & $\mathrm{ND} / \mathrm{AYU} / 4$ & 130163 & February 2014 & Rasendra Sara Sangraha & $55 / 10$ \\
\hline DMB & AYU-150 & P150700381 & July 2015 & SDS Monograph no-020009 & $64 / 10$ \\
\hline PGB & UA-AYU-67/2005 & GDB019 & March 2015 & AFI-I & $5 / 5$ \\
\hline BGB & $\mathrm{ND} / \mathrm{AYU} / 4$ & 140205 & June 2015 & Siddha yoga Sangraha & $55 / 10$ \\
\hline DGB & AYU-150 & P151100036 & November 2015 & SDS Monograph no-020003 & $53 / 10$ \\
\hline AGB & $\mathrm{GA} / 1701$ & BHE001 & April 2016 & RTS Vol1 & $40 / 10$ \\
\hline
\end{tabular}

NM: Not mentioned, GB: Godanti bhasma, AGB: Ayukalp GB, PGB: Patanjali GB, BGB: Baidyanath GB, DGB: Dhootapapeshwar GB, AMB: Ayukalp MB, PAB: Patanjal AB, BAB: Baidyanath AB, AAB: Ayukalp AB, PMB: Patanjali MB, BMB: Baidyanath MB, DMB: Dhootapapeshwar MB, AB: Abhraka bhasma, MB: Mandoor bhasma, DAB: Dhootapapeshwar abhraka bhasma, RTS: Rasa tantra sara, AFI: Ayurvedic formulary of India, SDS: Shree Dhootapapeshwar Standards 
Table 2: Elemental concentrations in Abhraka bhasmas in $\mathrm{mg} / \mathrm{l}$ by atomic absorption spectroscopy

\begin{tabular}{|c|c|c|c|c|}
\hline Elements/RDI* & РАВ & BAB & DAB & AAB \\
\hline $\mathrm{Mg} / 350 \mathrm{mg} *$ & $7.319 \pm 0.05$ & $6.065 \pm 0.01$ & $2.358 \pm 0.03$ & $3.535 \pm 0.01$ \\
\hline $\mathrm{Al} / 1.0 \mathrm{mg} / \mathrm{kg}$ of body weight (FAO/WHO 2007) $[15,16]$ & $36.801 \pm 0.50$ & $1.771 \pm 0.01$ & $14.908 \pm 0.02$ & $3.801 \pm 0.07$ \\
\hline $\mathrm{K} / 3500 \mathrm{mg}[17]$ & $8.537 \pm 0.68$ & $5.467 \pm 0.04$ & $6.505 \pm 0.06$ & $2.638 \pm 0.01$ \\
\hline $\mathrm{Ca} / 1000 \mathrm{mg}^{*}[18]$ & $6.432 \pm 0.29$ & $13.071 \pm 0.04$ & $3.318 \pm 0.02$ & $1.388 \pm 0.01$ \\
\hline $\mathrm{Cr} / 120 \mu \mathrm{g} *$ & $2.373 \pm 0.38$ & $0.095 \pm 0.005$ & $0.163 \pm 0.006$ & $0.055 \pm 0.005$ \\
\hline $\mathrm{Mn} / 5 \mathrm{mg}^{*}$ & $1.871 \pm 0.16$ & $0.26 \pm 0.02$ & $0.189 \pm 0.01$ & $0.075 \pm 0.005$ \\
\hline $\mathrm{Fe} / 15 \mathrm{mg}^{*}$ & $19.908 \pm 0.09$ & $17.181 \pm 0.04$ & $11.725 \pm 0.02$ & $6.159 \pm 0.04$ \\
\hline $\mathrm{Zn} / 15$ mg* & $0.139 \pm 0.03$ & $0.147 \pm 0.007$ & $0.048 \pm 0.01$ & $0.025 \pm 0.007$ \\
\hline Mo/0.1-0.3 mg* & $0.545 \pm 0.04$ & $1.373 \pm 0.01$ & $0.255 \pm 0.03$ & $0.186 \pm 0.01$ \\
\hline $\mathrm{Cd} / 25 \mu \mathrm{g} / \mathrm{kg}$ body weight [19] & $0.009 \pm 0.003$ & $0.006 \pm 0.001$ & $0.007 \pm 0.001$ & $0.008 \pm 0.001$ \\
\hline
\end{tabular}

Values are expressed as mean $\pm \mathrm{SD}(\mathrm{n}=2)$. ${ }^{*} \mathrm{RDI}$ : Recommended daily intake, PAB: Patanjali AB, BAB: Baidyanath AB, DAB: Dhootapapeshwar abhraka bhasma,

AAB: Ayukalp AB are four ayurvedic companies, AB: Abhraka bhasma, SD: Standard deviation, FAO: Food and Agriculture Organization of the United Nations

Table 3: Elemental concentrations in Mandoor bhasmas in $\mathrm{mg} / \mathrm{l}$ by atomic absorption spectroscopy

\begin{tabular}{|c|c|c|c|c|}
\hline Elements/RDI* & РМВ & ВMB & DMB & АMB \\
\hline $\mathrm{Mg} / 350 \mathrm{mg}^{*}$ & $5.393 \pm 0.02$ & $1.129 \pm 0.02$ & $0.861 \pm 0.02$ & $5.735 \pm 0.21$ \\
\hline $\mathrm{Al} / 1.0 \mathrm{mg} / \mathrm{kg}$ of body weight (FAO/WHO 2007) $[15,16]$ & $4.111 \pm 0.01$ & $2.157 \pm 0.04$ & $4.918 \pm 0.02$ & $11.203 \pm 0.01$ \\
\hline $\mathrm{K} / 3500 \mathrm{mg}[17]$ & $4.349 \pm 0.03$ & $0.967 \pm 0.02$ & $2.764 \pm 0.009$ & $4.311 \pm 0.01$ \\
\hline $\mathrm{Ca} / 1000 \mathrm{mg}^{*}[18]$ & $11.288 \pm 0.01$ & $3.929 \pm 0.04$ & $7.774 \pm 0.01$ & $12.92 \pm 0.01$ \\
\hline $\mathrm{Cr} / 120 \mu \mathrm{g}^{*}$ & $0.951 \pm 0.01$ & $0.091 \pm 0.003$ & $0.317 \pm 0.02$ & $0.072 \pm 0.004$ \\
\hline $\mathrm{Mn} / 5 \mathrm{mg} *$ & $3.855 \pm 0.02$ & $1.049 \pm 0.04$ & $1.254 \pm 0.03$ & $1.321 \pm 0.005$ \\
\hline $\mathrm{Fe} / 15 \mathrm{mg}^{*}$ & $21.704 \pm 0.21$ & $20.606 \pm 0.02$ & $20.755 \pm 0.007$ & $19.272 \pm 0.009$ \\
\hline $\mathrm{Zn} / 15 \mathrm{mg} \mathrm{g}^{*}$ & $0.281 \pm 0.32$ & $0.025 \pm 0.005$ & $0.064 \pm 0.007$ & $0.015 \pm 0.005$ \\
\hline Мo/0.1-0.3 mg* & ND & ND & $0.172 \pm 0.009$ & $0.2305 \pm 0.01$ \\
\hline $\mathrm{Cd} / 25 \mu \mathrm{g} / \mathrm{kg}$ body weight [19] & ND & ND & $0.0485 \pm 0.05$ & $0.010 \pm 0.001$ \\
\hline
\end{tabular}

Values are expressed as mean \pm SD $(n=2) . *$ RDI: Recommended daily intake. PMB: Patanjali MB, BMB: Baidyanath MB, DMB: Dhootapapeshwar MB, AMB: Ayukalp MB, ND: Not detected, MB: Mandoor bhasma, FAO: Food and Agriculture Organization of the United Nations

Table 4: Elemental concentrations in Godanti bhasmas in mg/l by atomic absorption spectroscopy

\begin{tabular}{|c|c|c|c|c|}
\hline Elements/RDI* & PGB & BGB & DGB & AGB \\
\hline $\mathrm{Mg} / 350 \mathrm{mg}^{*}$ & $0.559 \pm 0.01$ & $0.244 \pm 0.03$ & $0.041 \pm 0.005$ & $0.024 \pm 0.007$ \\
\hline $\mathrm{Al} / 1.0 \mathrm{mg} / \mathrm{kg}$ of body weight (FAO/WHO 2007) $[15,16]$ & $2.95 \pm 0.007$ & $1.762 \pm 0.004$ & $0.255 \pm 0.01$ & $0.082 \pm 0.01$ \\
\hline $\mathrm{K} / 3500 \mathrm{mg}[17]$ & $0.308 \pm 0.009$ & $0.189 \pm 0.01$ & $0.026 \pm 0.006$ & $0.035 \pm 0.007$ \\
\hline $\mathrm{Ca} / 1000 \mathrm{mg}^{*}[18]$ & $15.379 \pm 0.007$ & $15.143 \pm 0.01$ & $14.52 \pm 0.02$ & $14.572 \pm 0.02$ \\
\hline $\mathrm{Cr} / 120 \mu \mathrm{g}^{*}$ & $0.063 \pm 0.007$ & $0.072 \pm 0.002$ & $0.086 \pm 0.006$ & $0.02 \pm 0.001$ \\
\hline $\mathrm{Mn} / 5 \mathrm{mg}^{*}$ & $0.035 \pm 0004$ & $0.051 \pm 0.01$ & $-0.008 \pm 0.001$ & $0.016 \pm 0.004$ \\
\hline $\mathrm{Fe} / 15 \mathrm{mg}^{*}$ & $0.225 \pm 0.005$ & $0.33 \pm 0.02$ & $0.142 \pm 0.009$ & $0.094 \pm 0.004$ \\
\hline $\mathrm{Zn} / 15 \mathrm{mg}^{*}$ & $0.016 \pm 0.001$ & $0.031 \pm 0.006$ & $-0.006 \pm 0.001$ & $0.006 \pm 0.0003$ \\
\hline Mo/0.1-0.3 mg* & $0.162 \pm 0.06$ & $0.225 \pm 0.01$ & $0.186 \pm 0.12$ & $0.2095 \pm 0.004$ \\
\hline $\mathrm{Cd} / 25 \mu \mathrm{g} / \mathrm{kg}$ body weight [19] & $0.0067 \pm 0.004$ & $0.008 \pm 0.001$ & $0.007 \pm 0.002$ & $0.002 \pm 0.002$ \\
\hline
\end{tabular}

Values are expressed as mean \pm SD ( $n=2$ ). *RDI: Recommended daily intake, PGB :Patanjali GB, BGB: Baidyanath GB, DGB: Dhootapapeshwar GB, AGB: Ayukalp GB, GB: Godanti bhasma, FAO: Food and Agriculture Organization of the United Nations, SD: Standard deviation

All the four brands $\mathrm{AB}$ vary in the elemental constituent, and there is considerable difference of each manufacturer $\mathrm{AB}$.

Aluminum (Al) is found higher in concentrations, in Patanjali abhraka bhasma (PAB) (36.801 mg/l), Dhootapapeshwar abhraka bhasma (DAB) (14.908 mg/l), Ayukalp abhraka bhasma (AAB) (3.801 mg/l), and Baidyanath abhraka bhasma (BAB) $(1.771 \mathrm{mg} / \mathrm{l})$ in descending order. However, as per RDI, only $1-\mathrm{mg} / \mathrm{kg}$ body weight is good for health, variation in quantity may cause effect on health.

Similarly, chromium (Cr) presents in higher concentration in $\mathrm{PAB}$ $(2.373 \mathrm{mg} / \mathrm{l})$ and DAB $(0.163 \mathrm{mg} / \mathrm{l})$, because the RDI level of $\mathrm{Cr}$ is $0.120 \mathrm{mg} /$ day, and in $\mathrm{BAB}$ and $\mathrm{AAB}$ found below the RDI level, if it is consumed regularly means, there may arise health problems, so the care must be taken while advising bhasmas to patients depending on their elemental constitutes present.
Molybdenum (Mo) is also present higher in concentration than daily requirement $(0.1-0.3 \mathrm{mg})$ in two brand bhasmas, i.e. PAB $(0.545 \mathrm{mg} / \mathrm{l})$ and $B A B(1.373 \mathrm{mg} / \mathrm{l})$ and below the value of estimated requirement in $\mathrm{DAB}$ and $\mathrm{AAB}$.

Cadmium (Cd): The provisional tolerable monthly intake of cadmium is $25 \mu \mathrm{g} / \mathrm{kg}$ body weight, as established by the joint Food and Agriculture Organization of the United Nations (FAO)/WHO Expert Committee on Food Additives (JECFA) in 2010 [19]. It is found below the daily requirement in all four brand bhasmas, and thus, the $A B$ is free from toxicity in terms of their elemental constitutes.

It seems that the $\mathrm{AB}$ of four brands is rich in micro and trace elements, and, there is a variation in concentrations of individual elements in four brands. This tells the difference in quality of $\mathrm{AB}$ from manufacturer to manufacture, which impacts on the balancing of all nutrients in the human body, because if any one of the trace elements becomes high in 
body, it can affect the function of other important trace minerals in body; Because of the impairment action of elements in body, the presence of quantity of each elements in the bhasmas should be checked, whether it is in the permissible range or not, before directing it to the patients, also care should taken about the presence of toxic elements.

\section{Mandoor bhasma}

It is used in treatment of disease like Anemia, hepatic disorder, Jaundice etc. FAAS analysis results of MB by four manufacturers were presented in Table 3. MB is found rich in $\mathrm{Fe}, \mathrm{Ca}, \mathrm{K}, \mathrm{Al}, \mathrm{Mg}$, and all other elements are present in trace amount.

The MB was found to be rich in $\mathrm{Mg}, \mathrm{Al}, \mathrm{K}, \mathrm{Ca}, \mathrm{Mn}$, and $\mathrm{Fe}$ in all the manufacturer bhasma. Here also, aluminum (Al) is higher than the RDI level in AMB (11.203 mg/l), Dhootapapeshwar mandoor bhasma (DMB) $(4.918 \mathrm{mg} / \mathrm{l})$, PMB (4.111 mg/l), and BMB $(2.157 \mathrm{mg} / \mathrm{l})$.

Chromium (Cr) RDI value is $120 \mu$ g, i.e., $0.12 \mathrm{mg} /$ day, but in $\mathrm{PAB}$ $(0.951 \mathrm{mg} / \mathrm{l})$ and in DMB $(0.317 \mathrm{mg} / \mathrm{l})$ found in higher than the required amount, this may cause toxic effect. Moreover, in BMB and $\mathrm{AMB}$, it is below the RDI value; in this case, there is no cause of adverse effects. Manganese (Mn) is found below the RDI level; coming to Iron (Fe), it is found 2-3 mg higher than the RDI, because this drug or bhasma is advised in case of iron-deficiency problems, such as anemia and jaundice, so the level of iron in this bhasma seems to be acceptable.

Cd and Mo are not found in PMB and BMB and found present in DMB and AMB. Moreover, Mo is present higher in AMB, where $\mathrm{Cd}$ is found higher in DMB than the required amount.

The all above facts reflect the changes in MB from one manufacturer to other.

\section{Godanti bhasma}

It improves strength and immunity and is used in the treatment of headache, leukorrhea, and fever due to pitta imbalance, chronic fever, anemia, cough, cold, asthma, chest injury, emaciation, and wasting in children. FAAS analysis results of GB were presented in Table 4.

From the present analysis, it was found that GB contains calcium (Ca) as rich element, because it is calcium based bhasma, it was prepared by gypsum as per literature review, and the concentration of Ca content present in four brands is nearly equal; all other detected elements were present in trace amount.

Like the $\mathrm{AB}$ and $\mathrm{MB}, \mathrm{GB}$ also contains aluminum ( $\mathrm{Al}$ ) and it is present higher in $\mathrm{PGB}$ and $\mathrm{BGB}$. Moreover, in DGB and AGB, it is below the required amount.

Magnesium (Mg), potassium (K), chromium ( $\mathrm{Cr}$ ), manganese (Mn), zinc $(\mathrm{Zn})$, molybdenum (Mo), and cadmium (Cd) is found below the RDI level in all the four brand GBs.

Aluminum (Al) daily intake is $1 \mathrm{mg} / \mathrm{kg}$ body weight (WHO/FAO 2007), as the body weight increases aluminum (Al) intake should also increase; on the basis of this, $\mathrm{Al}$ is the maximum constitutes of Divya Patanjali brand bhasmas.

In all three bhasma, the toxic metal cadmium was present below the permissible limit of intake; hence, there is no risk of cadmium in all the bhasmas of four brands except in DMB $(0.0485 \mathrm{mg} / \mathrm{l})$, because it is found above the recommended level, and the present analysis shows the variation in individual elements' concentration of bhasmas from one manufacturer to another because of this variation in elemental content which may lead to the change of quality of the bhasmas.

This study emphasizes that by knowing the amount of elemental contents in bhasma and their permissible limit or range one can predict the quality of the bhasma product by different manufacturer.

\section{CONCLUSION}

From the present study, Divya Patanjali brand bhasmas were found rich in aluminum( $\mathrm{Al})$, magnesium $(\mathrm{Mg})$, potassium $(\mathrm{K})$, chromium $(\mathrm{Cr})$, manganese $(\mathrm{Mn})$, and copper $(\mathrm{Cu})$; it concludes that the ayurvedic bhasma prepared by different brands differ in quality, as there is variation in elemental concentration which may imbalance the human body functioning, by impairing the nutrients. However the body in good health condition can only be maintained, by balancing the required level of intake of mineral to body, through the knowledge of correct and proper diet supplements. For the proper diet supplement regarding minerals and metals in body, further work on bhasmas are needed, regarding bhasmas constituents and there quantity. Moreover, intake of each and individual elements should be taken care, before bringing/releasing to market al.o while prescribing medicine to patients.

\section{ACKNOWLEDGMENT}

The author Ashwini A is thankful to UGC New Delhi for awarding BSR fellowship.

\section{AUTHOR'S CONTRIBUTION}

Ashwini A has completed the manuscript by analysis the data and literature survey and B R Kerur has guided and corrected the manuscript.

\section{CONFLICT OF INTEREST}

Authors declared there is no any conflict of interest.

\section{REFERENCES}

1. Sharma R, Prajapati PK. Nanotechnology in medicine: Leads from ayurveda. J Pharm Bioallied Sci 2016;8:80-1

2. Ashwini A, Kerur BR. Estimation of heavy and trace elements in ayurvedic drug (loha bhasma) alternative medicine for anemia by AAS and ICP-OES. Int J Res Aturvedia Pharm 2017;8:81-5.

3. Tripathi YB. A multidisciplinary approach to standardize bhasmas (ayurvedic metallic preparations) Curr Sci 2006;90:897-8.

4. Arya RK. Characterization of bioactive nanoparticles-bhasma an Indian ayurveda drug. Indian J Pharm Educ Res 2014;48:61-8.

5. Mulchand S, Seema M. Formulation of polyherbomineral matrices for treatment of osteoporosis. Asian J Pharm Clin Res 2018:11:217-23.

6. Chitnis KS, Stanley A. Chemical evaluation of tamra bhasma. Int J Pharm Bio Sci 2011;2:160-8.

7. Gupta RK, Lakshmi V, Jha CB. X-ray diffraction of different samples of swarna makshika bhasma. Ayu 2015;36:225-9.

8. Mishra A, Mishra AK, Tiwari OP, Jha S. In-house preparation and characterization of an ayurveda bhasma: Praval bhasma. J Integr Med 2014; $12: 52-8$

9. Kumar A, Nair AG, Reddy AV, Garg AN. Availability of essential elements in bhasmas: Analysis of ayurvedic metallic preparations by INAA. J Radioanal Nucl Chem 2006;270:173-80.

10. Monali BV, Vishal VP, Sarita SP. Formulation, standardization and comparative evaluation of ancient nanomedicine varatika bhasma. Int J Pharm Drug Anal 2015;3:126-33.

11. Gawate RP, Kilor VA, Sapkal NP. Physicochemical characterization and hepatoprotective activity of mandur bhasma. Int J Pharm Pharm Sci 2016;8:327-32

12. Santoshi V, Shakila BA, Kurian GA. Synthesis, characterization and biological evaluation of iron oxide nanoparticles prepared by Desmodium gangeticum root aqueous extract. Int J Pharm Pharm Sci 2014;7 Suppl 1:75-80

13. Krupanidhi S, Sreekumar A, Sanjeevi CB. Copper and biological health. Indian J Med Res 2008;128:448-61.

14. Delfgauw: Recommended Daily Intake of Vitamins and Minerals. Available from: https://www.lenntech.com/recommended-daily-intake. $\mathrm{htm}$.

15. Schafer U, Seifert M. Oral intake of aluminum from foodstuffs, food additives, food packaging, cookware and pharmaceutical preparations with respect to dietary regulations. Trace Elem Electrolytes 2006;23:150-61.

16. WHO. Aluminium in Drinking Water; 2010. Available from: https:// 
www.who.int/water sanitation health/waterquality/guidelines/ chemicals/aluminium.pdf?ua $=1$.

17. WHO. Guideline: Potassium Intake for Adults and Children; 2012. Available from: https:/www.who.int/nutrition/publications/guidelines/ potassium_intake_printversion.pdf; https://www.who.int/elena/titles/ guidance_summaries/potassium_intake/en/.
18. WHO. Calcium and Magnesium in Drinking-Water Public Health Significance; 2009. Available from: https://www.who.int/water_ sanitation_health/publications/publication_9789241563550/en/.

19. WHO. Exposure to Cadmium: A Major Public Health Concern; 2010. Available from: https://www.who.int/ipcs/assessment/public_health/ cadmium/en 